\title{
Sağlık Bakanı Fahrettin Koca'nın Covid-19 Salgınında Sergilediği Dijital Liderliğin Analitik Hiyerarşi Süreciyle İncelenmesi (Twitter Vaka Çalışması) \\ (Examination of the Digital Leadership Exhibited by the Minister of Health Fahrettin Koca in the Covid-19 Outbreak with the Analytical Hierarchy Process (Twitter Case Study)
}

\section{Sefer AYDOĞAN (iD) a Fatma KUTLU GÜNDOĞDU (iD) b \\ aMilli Savunma Üniversitesi, Hava Harp Okulu Dekanlığı, Beşeri ve Sosyal Bilimler Bölümü, Yeşilyurt, İstanbul. Türkiye. saydogan@hho.msu.edu.tr \\ bMillî Savunma Üniversitesi, Hava Harp Okulu Dekanlığı, Endüstri Mühendisliği Bölümü, Yeşilyurt, İstanbul, Türkiye. kgundugdu@hho.msu.edu.tr}

\begin{tabular}{|c|c|}
\hline MAKALE BİLGİSİ & ÖZET \\
\hline $\begin{array}{l}\text { Anahtar Kelimeler: } \\
\text { Stratejik yönetim } \\
\text { Twitter }\end{array}$ & $\begin{array}{l}\text { Amaç - Sağlık Bakanı Fahrettin Koca'nın Twitter paylaşımları ile etkileşim halinde olduğu } \\
\text { takipçilerinin davranışlarına yön vermek için sergilediği dijital liderliğin önem derecelerini beğeni, } \\
\text { yorum ve retweet unsurlarını gözeterek ortaya koymaktır. }\end{array}$ \\
\hline $\begin{array}{l}\text { Dijital Liderlik } \\
\text { Dönüşümsel Liderlik } \\
\text { Analitik Hiyerarşi Süreci }\end{array}$ & $\begin{array}{l}\text { Yöntem - Bu çalışmada Fahrettin Koca'nın paylaştığı } 1182 \text { tweet ve bu tweetlere ait beğeni, yorum } \\
\text { ve retweet sayılarından bir veri tabanı oluşturulmuştur. Çalışmada içerik analizi ve sezgisel bulanık } \\
\text { analitik hiyerarşi süreci bu veri tabanına entegre bir biçimde uygulanmıştır. }\end{array}$ \\
\hline $\begin{array}{l}\text { Gönderilme Tarihi } 27 \text { Mart } \\
2021 \\
\text { Revizyon Tarihi } 15 \text { Haziran }\end{array}$ & $\begin{array}{l}\text { Bulgular - Fahrettin Koca'nın salgın ile mücadelede sergilediği liderlik boyutları ile ilişkilendirilen } \\
\text { tweetlerin beğeni, yorum ve retweet sayıları gözetildiğinde en önemli liderlik boyutu vizyon liderlik } \\
\text { boyutudur. Bunu sırasıyla amaç, eğitim, öykünme ve eylem boyutu izlemektedir. Fahrettin Koca'nın } \\
\text { Twitter paylaşımlarına ilişkin retweetlerin önem derecesi beğeni ve yoruma göre daha fazladır. }\end{array}$ \\
\hline $\begin{array}{l}2021 \\
\text { Kabul Tarihi } 20 \text { Haziran } 2021\end{array}$ & $\begin{array}{l}\text { Tartışma - Fahrettin Koca, salgınla mücadeleye ilişkin Twitter üzerinden sergilediği liderlikte } \\
\text { takipçileri tarafından sağlıklı bir gelecek örüntüsü edinilmesine önem vermektedir. Toplum } \\
\text { sağlığının elde edilmesine katkı sağlamak maksadıyla takipçiler ile etkileşiminde retweet önem arz } \\
\text { etmektedir. }\end{array}$ \\
\hline
\end{tabular}

\begin{tabular}{|c|c|}
\hline ARTICLE INFO & ABSTRACT \\
\hline Keywords: & Purpose - To reveal the importance level of the digital leadership that the Minister of Health Fahrettin \\
\hline $\begin{array}{l}\text { Strategic management } \\
\text { Twitter }\end{array}$ & $\begin{array}{l}\text { Koca exhibited to guide the behaviors of his followers with whom he interacts with his Twitter posts, } \\
\text { by considering the likes, comments and retweets. }\end{array}$ \\
\hline Digital Leadership & Design/methodology/approach - In this study, a database was generated with 1182 tweets shared by \\
\hline $\begin{array}{l}\text { Transformational Leadership } \\
\text { Analytical Hierarchy Process }\end{array}$ & $\begin{array}{l}\text { Fahrettin Koca and the number of likes, comments and retweets belonging to these tweets. The content } \\
\text { analysis and heuristic fuzzy analytical hierarchy analysis were applied to this database in an } \\
\text { integrated manner. }\end{array}$ \\
\hline $\begin{array}{l}\text { Received } 27 \text { March } 2021 \\
\text { Revised } 15 \text { June } 2021 \\
\text { Accepted } 20 \text { June } 2021\end{array}$ & $\begin{array}{l}\text { Findings - Considering the number of likes, comments and retweets of the tweets associated with the } \\
\text { leadership exhibited by Fahrettin Koca in fighting with Covid-19, the most important leadership } \\
\text { dimension is vision. It is followed by purpose, education, emulation and action dimensions, } \\
\text { respectively. The importance of the retweets regarding the posts of Twitter of Fahrettin Koca is higher } \\
\text { than the likes and comments. }\end{array}$ \\
\hline $\begin{array}{l}\text { Article Classification: } \\
\text { Research Article }\end{array}$ & $\begin{array}{l}\text { Discussion - Fahrettin Koca attaches importance to be acquired of a healthy vision in fight with Covid- } \\
19 \text { by his followers. In this manner, retweet is important in interaction with followers in order to } \\
\text { contribute to the achievement of public health. }\end{array}$ \\
\hline
\end{tabular}

\section{Önerilen Atıf/ Suggested Citation}

Aydoğan, S., Kutlu Gündoğdu, F. (2021). Sağlık Bakanı Fahrettin Koca'nın Covid-19 Salgınında Sergilediği Dijital Liderliğin Analitik Hiyerarşi Süreciyle İncelenmesi (Twitter Vaka Çalışması), İşletme Araştırmaları Dergisi, 13 (2), 1737-1750. 


\section{S. Aydoğan - F. Kutlu Gündoğdu 13/2 (2021) 1737-1750}

\section{GIRISŞ}

2019'un aralık ayında, Çin'in Wuhan bölgesinde yeni ve bulaşıcı bir hastalık aniden ortaya çıkmıştır. 11 Şubat 2020'de Dünya Sağlık Örgütü (World Health Organization, (WHO)) hastalı̆̆ın yayılma hızını ve toplumsal sağlığı göz önünde bulundurarak hastalığ “ "Covid-19” adı ile küresel salgın olarak ilan etmiştir (World Health Organization, 2020). Covid-19 salgını küreselleşmenin etkisi ile Wuhan dışına sıçrayarak dünya için eşi görülmemiş bir krize neden olmuştur (Agarwal vd., 2020: 387).

Covid-19 salgını sosyal, ekonomik (Middleton vd., 2020: 1525-1527), psikolojik (Uzun vd. 2020: 358) ve tıbbi sorunlara (Kutikov vd., 2020: 2) neden olarak toplum üzerinde farklı etkiler yaratmakta (Bostan vd., 2020: 1) salgının etkilerini daha da yıkıcı hale getirmektedir (Wenzel vd., 2020: 8). Bu yüzden Covid-19 salgını yayılmaya devam ederken hükümetler, insanların hastalı̆̆ı birbirine bulaştırmasına neden olabilecek fiziki yakınlığı ortadan kaldırmak için sosyal yasaklar ve kapanmalar gibi güçlü önlemleri uygulamaktadır (Albers ve Rundshagen, 2020: 1). Alınan tedbirlerin amacı, ulusal sağlık sistemlerine ait Covid-19 tedavi kapasitesini aşacak vaka sayılarını önlemektir (Remuzzi ve Remuzzi, 2020: 1226). Bu bakımdan salgın ile mücadelede uygun tepkileri organize etmek ya da planlamak zaman almaktadır (Nathan, 2000: 12).

Salgınla mücadelede, mücadeleyi olumsuz etkileyen bir kavram olan "infodemik", salgın ile mücadele yönetimi esnasında toplumun yanlış bilgilendirme tehlikesi yüzünden salgının ilerlemesini ifade etmektedir (Zarocostas, 2020: 676). Bu bakımdan özellikle bilginin aracısız yayıldığı sosyal medya platformları insanların salgın ile çok miktarda içeriğe erişmesine ve davranışlarına güçlü bir şekilde yön vermesine imkân sağlamaktadır (Cinelli vd., 2020: 1). Çünkü insanlar artık sağlıkları ile ilgili son derece kişiselleştirilmiş bilgiler alabilmekte ve bu bilgiler davranışları değiştirebilmektedir (Sharot ve Sunstein 2020: 14). Dolayısıyla Covid19 salgını, sosyal medyanın toplum üzerindeki etkisini ortaya koymuştur (Cinelli vd., 2020: 1). Twiplomacy 2020 raporuna göre 189 ayrı ülkede kamu idarecilerin ve liderlerin sosyal medyada resmi varlıkları söz konusudur. Ayrıca dünya liderlerinin Covid-19 salgını esnasında Twitter'ı halkı salgın ile ilgili yanlış yönlendirmelerden korumak için kullandıklarını belirtmektedir (Twiplomacy, 2020). Bu bilgilerin kamu idarecilerinin yönettiği salgın sürecine ve bireysel davranışlara yön vermesindeki etkisi göz önünde bulundurulduğunda (Kim, 2011: 975), Covid-19 salgını ile mücadelede sosyal medya aracı olarak Twitter'ın önemi anlaşılmaktadır (Twiplomacy, 2020).

Bu kapsamda dünya çapında internet ve onun devamında sosyal medya kullanımları incelendiğinde; 2020 yılı itibari ile toplam nüfusun (7 milyar 750 milyon) 4 milyar 540 milyonu internet kullanıcıdır. Yine dünya çapında 3 milyar 800 milyon ise sosyal medya kullanıcı sayısı bulunmaktadır. Dünya çapında her bir sosyal medya kullanıcısının sosyal medyada günlük geçirdiği zaman 2 saat 24 dakikadır. Türkiye'de ise toplam nüfusa oranla internet kullanım yaygınlığ $1 \% 74$, sosyal medya kullanım yaygınlığı ise \%64'dür. Türkiye'de her bir internet kullanıcısının mobil telefon ile internette geçirdiği günlük ortalama zaman 4 saat, bilgisayar ile ise 3 saat 29 dakikadır. Her bir sosyal medya kullanıcısının ise sosyal medyada geçirdiği zaman 2 saat 51 dakikadır. Twitter'ın dünya çapında 340 milyon kullanıcısı mevcuttur. Türkiye'de ise 11 milyon 800 bin kullanıcısı mevcut olup Türkiye Twitter kullanımında dünyada 6'ıncı sırada yer almaktadır (Hootsuite Dijital, 2020). Dolayısıyla Twitter, Covid-19 salgını ile mücadelede kamu idareci tarafından takipçiler ile iletişime geçmek için sıklıkla kullanılan bir sosyal medya iletişim aracı olmuştur (Gamayanto vd., 2019: 119; Bilgiç ve Akyüz, 2020: 234; Twiplomacy, 2020).

Bununla birlikte toplum sağlığının kazanımı için bir liderlik altında vatandaşlar arasında iletişime, etkileşime ve uyuma ihtiyaç olduğu ifade edilmektedir (Özsalmanlı, 2005: 139). Ancak Covid-19 salgını ani geliştiği ve hızla yayıldığı için salgınla mücadelede belirsizlikler yaratmıştır. Bu belirsizliklerin ve neden olduğu karmaşanın ortadan kaldırılmasına katkı sağlamak için Türkiye Cumhuriyeti Sağlık Bakanı olarak Sn. Dr. Fahrettin Koca'da dünya çapındaki diğer kamu idarecileri gibi (Twiplomacy, 2020) sosyal medya aracı olarak Twitter'1 aktif olarak kullanmaktadır. Bu şekilde Fahrettin Koca takipçilerine Twitter üzerinden hızlı erişmekte ve takipçi davranışlarına yön verebilmektedir. Bu nedenle, salgınla mücadelede sosyal medya araçlarının kullanımına yönelik pek çok araştırma yapılmış olup Fahrettin Koca'nın salgınla mücadelede Twitter üzerinden sergilediği liderliğin araştırılması halk sağlığının edinilmesine yapacağı katkı gözetildiğinde önem arz etmektedir.

Fahrettin Koca'nın Twitter paylaşımları üzerine yapılan çalışmalar incelendiğinde: Kalçık ve Bayraktar (2020) çalışmasında 11 Mart 2020 ve 25 Mart 2020 tarihlerinde arasında tweet paylaşım sıklığı, tweet paylaşım türü, 


\section{S. Aydoğan - F. Kutlu Gündoğdu 13/2 (2021) 1737-1750}

tweet içeriği ve görsel tweet içeriklerini incelenmiş ve Fahrettin Koca'nın kriz iletişimi başarılı bulunmuştur. Bilgiç ve Akyüz (2020)'ün çalışmasında ise 11 Mart 2020 ile 10 Nisan 2020 tarihleri arasında Fahrettin Koca'nın Twitter paylaşımları incelenmiş, Twitter'da en çok hangi noktalara vurgu yaptığı, mesajlarının ne kadar etkileşim aldığı, dönem ve içerik olarak etkileşimlerde farklılaşma olup olmadığı içerik analizi ile incelenmiştir.

Mevcut çalışma ise Twitter üzerinden araştırmaya konu paylaşımların zaman aralığı, salgınla ilgili önemli mücadele aşamalarını kapsaması, Twitter etkileşimi ile sergilediği liderliğin Analitik Hiyerarşi Süreci (AHP) yöntemi ile incelenmesi bakımından diğer çalışmalardan farklılaşmaktadır.

\section{KURAMSAL ÇERÇEVE}

Çalışmayı detaylandırmak için, kamu idarecilerinin sosyal medya araçlarının liderliği sergilemede nasıl etkilediği, liderlik kavramını ve liderler ile takipçiler arasında nasıl ilişki kurulduğu açıklanmıştır.

\subsection{Liderlik}

Liderlik, liderin takipçileri tarafından kabul edildiğini (Gilbert ve Kelloway, 2018: 527) ve aralarında bir ilişki olduğunu ifade etmektedir (Conger et al., 2000; 747). Bu ilişki liderin takipçilerine yön verebilmesini sağladığından "ilişkisel liderlik" olarak belirtilmektedir (Northhouse, 2015: 92). Anılan ilişki örgütsel dönüşümü kolaylaştırmada kilit bir bileşendir (Metcalf, 2008: 9). Çünkü liderliğin görevi takipçilerinin içinde bulundukları durumu anlamalarını sağlamaktır (Smircich ve Morgan, 1982: 259). Liderler; takipçilerini davranışları (Seltzer ve Bass, 1990: 694) ve sözleri ile etkileyerek (Mayer-Schoenberger ve Oberlechner, 2002: 172) takipçilerinin ortak amacı elde etmesini sağlamaktadırlar. Dolaysıyla liderler takipçilerinin performanslarını arttırabilir (Pescosolido, 2001: 90). Bu sayede takipçileri içinde bulundukları zorluklarla yüzleşmeye hazırlayabilirler (Williams, 2015: 5). Gelişmekte olan ülkelerde liderin davranışı takipçilerin yönlendirilmesi ile başlar, besleyici-görev odaklı ve sürece katılımcı olacak şekilde ilerler. Türk toplumunda liderliğin ise takipçilerinin aileye olan aidiyet duyguları ile ilgilenen bir ebeveyn tarzında olduğu belirtilmektedir (Fikret Pasa vd., 2001: 556).

Son yıllarda, dönüşümsel liderliğin ortak amacın elde edilmesinde takipçilerin performansını arttıran bir liderlik tarzı olarak ön plana çıktığı ifade edilmektedir (Kalsoom vd., 2018; Judge ve Piccolo, 2004). Bu kapsamda dönüşümsel liderlik takipçilerine idealleştirilmiş etki, ilham veren motivasyon, entelektüel uyarım ve kişiselleştirilmiş değerlendirme yapmalarını sağlamaktadır (Van Eeden vd., 2008: 255). Bass ve Avolio'ya (1994) göre dönüşümsel liderin bazı amaçları gerçekleştirmek istediği ifade edilmektedir. Bunlar; a) vizyon: takipçileri etkilemek ve motive etmek, böylece onların içsel motivasyonları vizyonla uyumlu hale getirmek; b) öykünme: takipçileri için bir rol model olmak; c) amaç: cazip bir gelecek vizyonu iletmek (ilham verici motivasyon) ve uyumu artırmaya yardımcı olmak; ç) eylem: belirli ve somut önerilerde bulunarak yaratıcılığı teşvik etmek (entelektüel motivasyon); d) eğitim: onlara öğrenme ve kendini gerçekleştirme fırsatları sağlamaktır. Bu bağlamda dönüşümsel liderlik takipçilerinin moralini, motivasyonunu yükselten bir liderlik tarzıdır (Barbuto, 2005: 38). Dönüşümsel liderlik, takipçileri ile bilgi paylaşarak (Masa'deh vd., 2016) öğrenmelerini sağlamaktadır (Coad ve Berry, 1998: 164). Dolayısıyla, dönüşümsel liderlik sergileyen yöneticiler ile takipçileri arasında değişimin gerçekleştirilmesine yönelik olumlu bir ilişki mevcuttur (Herold vd., 2008: 346). Çünkü dönüşümsel liderlik takipçileri üzerinde güven oluşturmaktadır (Goodwin vd., 2011: 410). Bununla birlikte Covid-19 salgını yüzünden ortaya çıkan halk sağlı̆̆ı ile ilgili sorunlar ölçek olarak çok büyük ve karmaşı olup uzun vadeli çözümler gerektirmekte, toplumu aşındırmaktadır (Koh ve Jacobson, 2009: 199). Bu bakımdan halk sağlığına liderlik eden kamu idarecileri sosyal strateji, kişilerarası beceri alanları ve teknikler geliştirmelidirler (Koh ve McCormack, 2006: 102). Halk sağlığına liderlik eden yöneticilerin sınırları olmayan bir ortamda, birçok alanda kapasitelerin arttırmaları gerektirmektedir (Parks, 2005: 3).

$\mathrm{Bu}$ nedenle, liderlikten takipçilerin saygı ve güven duyabilecekleri, takipçileri güçlendirecek, salgınla mücadeleyi sahiplendirecek, fedakârlık yapmayı sağlayabilecek, mücadelede gelecekle ilgili hedef ve beklentileri net bir şekilde ortaya koyması beklenmektedir (Van Eeden vd., 2008: 255). Bu bakımından halk sağlığının edinilmesi için dönüşümsel liderlik tarzının sergilenmesi uygun bir liderlik tarzı olarak gözükmektedir. Fahrettin Koca'nın bireysel ve halk sağllğının edinilmesi için toplumsal dönüşümlerin sürdürülebilir bir şekilde gerçekleşmesinde sergilediği liderlik bu kapsamda önem arz etmektedir. 


\subsection{Dijital Liderlik}

İnternet üzerinden birbiri ile bağlı bilgi sistemlerin kullanılmaya başlamasından beri, bilgi teknolojisi aracıllı̆̆ ile yürütülen liderlik üzerine araştırmalar ve incelemeler yapılmaya devam eden bir konudur (Thite, 2000: 235). Bu bağlamda dijital liderlik bilgi teknolojileri ile etkileşim olarak tanımlanmaktadır (Aksal, 2015: 80). Dijital platformların kullanımı liderlerin etkinliğin de değişiklik yaratabildiğinden (Suarez vd., 2020: 1) dijital platformlar üzerinden kurulan iletişim araçları liderliğin yürütülmesi için önemli bir araç haline gelmiş (Narbona, 2016: 93) ve kamu idarecileri dijital platformları kullanmaya başlamışlardır (Wirtz vd., 2020: 39).

Küresel salgına neden olan Covid-19'un toplum sağlığını nedenli etkilediği düşünüldüğünde, Fahrettin Koca'nın sağlık bakanı olarak bu salgınla mücadelenin başarılı olabilmesi için liderlik etkisini arttırma ihtiyacı ortaya çıkmaktadır. Dijital liderlikte; bilgi paylaşımına, sosyal medya araçlarını kullanımına ve teknolojiyi iletişim ağlarına entegre etmeye vurgu yapılmaktadır (Aksal, 2015: 78). Bu sayede toplum salgın ile mücadelede eğitilmiş ve yönlendirilmiş olacaktır. Öte yandan Covid-19 ile mücadele esaslarının zaman içerisinde ortaya çıktığı bu süreçte topluma farklı kaynaklardan infodemik bilgilerin de yer aldığı öneriler sunulmaktadır. Bu durum da bireylerin bilgiye dayalı güçlendirici etkileşimini (Ardi vd., 2020) etkileyebilmektedir. Böyle bir süreçten geçen toplumun doğru bilgilendirilmesi ve yönlendirilmesi için kamu idarecilerinin liderliklerine ihtiyaç artmaktadır. Fahrettin Koca sağlık bakanı olarak dijital platformlar üzerinden sergilediği liderlikle bu konudaki esasları ve gündemi (Bilgiç ve Akyüz, 2020) belirlemeye devam etmektedir.

\subsection{Twitter'in Dijital Liderlikteki Rolü}

Kişisel aktiviteler hakkında sık sık kısa mesajlar göndererek ile içerik paylaşımın yapılması olarak ifade edilen mikroblog (Merriam-Webster, 2021) herhangi bir gelişmeyi en hızlı duyuran dijital platformdur (Blog.Protan, 2021). Twitter gönderileri herkese açık olarak dağıtılmakta ve tüm kullanıcılar tarafından kolayca görüntülenebilmektedir (Park, 2013: 1641). Twitter bir mikroblog olarak açık sistemi, kullanıcıların diğer kullanıcılara yanıt vermesi için bir alan yaratmakta ve böylece onu kamusal söylem için canlı bir forum haline getirmektedir (Kim, 2011: 971). Bu özelliği Twitter'ı bireyleri etkilemede kullanılabilen güçlü bir sosyal medya aracı haline getirmektedir (Ingerson ve Bruce, 2013: 75). Burston (2015) Twitter üzerinden sergilenen liderliğin ölçümü için kullanılan değişkenleri şu şekilde sırlamaktadır: a) takipçi sayısı; takipçisinin çok olması ile mesajların potansiyel olarak etkisinin olacağını ifade etmesi, b) etki derecesi; retweet sayısı ya da mesajlarını yanıtlayan kullanıcılar sayısı ile ölçülmesini ifade etmesi ve c) konuşma seviyeleri; takipçileri ile olan konuşmaları ile her tweetin diğer kullanıcılar ile olan konuşma başlatması ile ölçülmektedir. Bunla birlikte paylaşılan tweetlerin retweet edilmesi orijinal tweetin takipçi sayısı ne olursa olsun ortalama 1.000 kullanıcıya ulaşacağını ortaya koymaktadır (Kwak vd., 2010: 590).

Bu bağlamda, 2004 yılından bu yana olası bir salgın için planlar ve hazırlıklar üzerinde çalışan Sağlık Bakanlığının (Koca, 2020) yöneticisi olarak Fahrettin Koca' da toplumu salgın ile mücadele konusunda bilgilendiren ve tedbirler almaya davet eden içerikleri ile Twitter kullandığı ve takipçi sayısının önemli ölçüde artış gösterdiği belirlenmiştir (Bilgiç ve Akyüz, 2020: 238). Sağlık Bakanı Fahrettin Koca'nın Twitter'da @drfahrettinkoca kullanııı adı ile 6.943.144 milyon takipçisi olup günlük 4.071, haftalık 42.915 ve aylık 153.528 takipçi artışı mevcuttur. (Boomsocial, 2021).

Tablo 1'de Covid-19 salgının Türkiye'de ilk vakasının görüldüğü 11 Mart 2020 ve aşının Türkiye'ye geldiği 31 Ocak 2021 tarihleri arasında Twitter'da yer alan tweet sayısı ile Twitter takipçi artış sayısı gösterilmektedir (Socialblade, 2020). 
Tablo 1. @drfahrettinkoca Kullanıcısının Aylara Göre Tweet Sayısı ve Takipçi Artışları

\begin{tabular}{lcc}
\hline & Tweet sayısı & Takipçi Artış Sayısı \\
\hline Mart-2020 & 170 & 3.919 .175 \\
Nisan & 152 & 894.249 \\
Mayıs & 166 & 387.796 \\
Haziran & 161 & 251.592 \\
Temmuz & 141 & 128.474 \\
Ağustos & 166 & 189.300 \\
Eylül & 136 & 147.474 \\
Ekim & 159 & 67.218 \\
Kasım & 230 & 178.026 \\
Aralık & 175 & 170.266 \\
Ocak-2021 & 103 & 122.290 \\
\hline
\end{tabular}

Tablo 1'de görüldüğü üzere takipçi sayısı 3.919.175 milyon kullanıcı ile önemli bir artış sergilemiştir. Bu bakımdan Fahrettin Koca'nın Twitter üzerinden Covid-19 salgını ile mücadele ile paylaştığı tweetler ile Covid19 salgını konusunda, çevrimiçi bir referans noktası ve iyi bir bilgi kaynağı (Hwang, 2015) haline geldiği söylenebilinir. Her ne kadar takipçi sayısı liderin takipçilerinin etkileme yeteneğinin doğrulaması olmasa da (Cha vd., 2010) Twitter üzerinden yürütülmek istenen liderliğin potansiyeli olduğunu ifade etmektedir (Narbona, 2016: 96).

\section{YÖNTEM}

\subsection{Araştırmanın Amacı ve Önemi}

$\mathrm{Bu}$ çalışmanın amacı, Fahrettin Koca'nın dijital bir platform olan Twitter kullanımı üzerinden sergilediği liderliğin beğeni, yorum ve retweet unsurları gözetilerek önem derecelerini ortaya koymaktır. Covid-19 salgını ile mücadelede bilimsel esaslarının keşifleri salgının yayılma hızından geride kaldığından, bireylerin mücadeleye ilişkin davranışlarında belirsizlikler meydana gelmektedir. Aralık Değerli Sezgisel Bulanık Analitik Hiyerarşi analizi, bu birey davranışlarında belirsizliğin giderilmesi için sergilenen liderliğin önem derecelerinin belirlenmesini sağlamaktadır. Çünkü liderliğin amacı bireyin davranışlarını ortak amaç için yön vermektir (Kotter, 2011 :24). Önem dereceleri belirlenmiş Twitter üzerinden sergilenen liderlik boyutları sonucunda, sürdürülegelen liderliğin toplum sağlığının edinilmesine yaptığı katkının etkinliği Covid-19 vaka sayıları ile mukayese edilebilecektir.

$\mathrm{Bu}$ amaçla araştırma kapsamında şu sorulara cevaplar aranmıştır.

1. Fahrettin Koca'nın dijital bir platform olan Twitter kullanımı üzerinden sergilediği liderliğin beğeni, yorum ve retweet unsurları gözetilerek önem dereceleri nelerdir?

2. Fahrettin Koca'nın Twitter paylaşımlarına ilişkin retweet, beğeni ve yorumun önem dereceleri nelerdir?

\subsection{Evren ve Örneklem}

Bu çalışmada Twitter üzerinden Fahrettin Koca'ya ait @drfahrettinkoca kullanıcısının salgının ilk vakasının görüldüğü 11 Mart 2020 ile aşının ülkede kullanıma sunulduğu 31 Ocak 2021 tarihleri arasında paylaştığ1 tweetler incelenmiştir. İnceleme için Twitter mikrobloku @drfahrettinkoca kullanıcı sayfasından keşfet bölümüne "from:drfahrettinkoca since:2020-03-11 until:2021-01-31" kodu girilerek belirtilen tarihler arasinda tüm tweetler görüntülenmiştir. Araştırma sınırlılıkları dahilinde Fahrettin Koca'nın 1182 tweeti analize alınmıştır (Socialblade, 2021).

\subsection{Araştırmanın Varsayımları ve Sinırlılıkları}

Araştırmanın sınırlılıkları ise aşağıda olduğu gibidir:

1. Araştırma zaman yönünden ilk Covid-19 vakasının görüldüğü 11 Mart 2020 ile aşının ülkede kullanıma sunulduğu 31 Ocak 2021 tarihleri arasında sinırlıdır.

2. Analize alınan tweetlerin sayısı konusunun Covid-19 ile mücadele olması, aynı tweetin tekrar tweet edilmesi ile sinırlıdır. 


\section{S. Aydoğan - F. Kutlu Gündoğdu 13/2 (2021) 1737-1750}

3. Dijital liderlik boyutları Bass ve Avilio (1994) tarafından ortaya konan dönüşümsel liderliğin gerçekleştirilmesi beklenen beş boyutu ile sınırlıdır.

\subsection{Verinin Toplanması}

$\mathrm{Bu}$ çalışmada çalışmanın amacına uygun olarak karma araştırma yönetimi kullanılmıştır. Çalışma için Twitter'da araştırmaya konu paylaşılan tweet içeriklerinin kamuya açık olması ve herkes tarafından erişebilmesi gerekçesi ile etik kurul izni alınmamıştır (Ör; Kalçık ve Bayraktar, 2020; Bilgiç ve Akyüz, 2020). Çalışmada kullanılan araştırma yöntemi üç aşamadan oluşmaktadır. İlk aşamada ikinci ve üçüncü aşamaya veri sağlaması amacı ile içerik analiz yöntemi (Neuendorf ve Kumar, 2015) kullanılmıştır. İçerik analizinde büyük veriler sosyal medya platformları arkasındaki programlar tarafından toplanan ve arşivlenen bilgi biçimini içermekte olup özellikle Twitter'dan, bu bilgilerin çoğu ücretsiz olarak edinebilinir ve belirli parametrelere göre incelenebilmektedir (Lewis vd.,2013).

Bu aşamadan sonra, Microsoft Excel formatında sayı, tarih, kategori, tweet, yorum sayısı, retweet ve beğeni sütunları olacak şekilde bir format oluşturulmuştur. Microsoft Excel veri tabanları bilgilere erişmek, analiz etmek ve rapor hazırlamak için kullanılmaktadır (Claussv, 2010). Görüntülenen her bir tweet bu excel formatına belirtilen zaman aralığı, konusunun Covid-19 ile mücadele olması, ayn tweetin tekrar tweet edilmesi kısıtları göz önünde bulundurularak ele alınmıştır. Bu kapsamda Fahrettin Koca'nın 1182 tweet paylaştığı tespit edilmiştir. Sonra incelenen her bir tweet, tweete ait yorum sayısı, her bir tweetin retweet sayısı okunarak belirtilen formata aktarılmıştır.

Çalışmada tweetlerin hangi liderlik boyutuna ait olduğunu belirlemek için; Bass ve Avilio (1994) tarafından ortaya konan dönüşümsel liderliğin gerçekleştirilmesi beklenen beş boyutuna göre sınıflandırılmıştır. Bunlar; a) vizyon (viz): Fahrettin Koca'nın takipçilerini salgın ile mücadelede doktrine etmeyi sağlayan ve gelecekte toplum sağlığının elde edilmesi vizyonunu ortaya koyan tweetler ve salgın ile mücadelede Fahrettin Koca'nın takipçileri ile birleşmelerini sağlayacak fikirlere odaklanmasını sağlayan tweetler. Ör.; Yeni yılı İstanbul Avrupa Yakası Komuta Kontrol Merkezi'nde, görevleri başındaki çalışma arkadaşlarımızla karşıladık. Sağlık çalışanlarımızın gayreti, milletimizin desteğiyle 2021 salgını bitiren yıl olacaktır. "Sağglık Çalışanları Yılı" tarihe onların başarısı, b) öykünme (öy): Fahrettin Koca'nın takipçilerini salgın ile mücadeleye örtük olarak katılmaya davet eden tweetler. Ör.: COVID-19, çok sayıda hekim yetiştirmiş bir hocamızı bizden aldı. Cerrahpaşa Tıp Fakültesi emekli öğretim üyelerinden Prof. Dr. Feriha Öz'ü kaybettik. Kendisine Allah'tan rahmet diliyorum. Ailesinin, Tıp Camiamızın başı să̆ olsun, c) amaç (amç): Fahrettin Koca'nın gelecekte mücadelede başarılı olmayı planladığını ve takipçilerini mücadelede başarılı olmaya çağırdığı tweetler. Ör: Bugün yapılan testlerde pozitif sonuç 51'dir. Toplam hasta sayımı 98 olmuştur. Hastalığın ağır seyrettiği kişiler, direnci düşük ve başka hastalığı olan kişilerdir. Yaşlılar yüksek risk grubundandır. Herkesi tedbirlere harfiyen uymaya davet ediyorum, ç) eylem (ey): Fahrettin Koca'nın takipçilerine belirli bir eylemi önerdiği, takipçilerin gerçekleştirebileceği görevleri içeren tweetler. Ör.: Saat 21.00 alkışı için sağ ol TüRKIYYE! Şehir şehir, ev ev çağrımıza uydun. Özverili sağlık çalışanlarımıza alkışınla güç verdin. Yarın, ertesi gün aynı saatte minnettarlığımızın sesi tekrar duyulsun! ÜST ÜSTE ÜÇ GÜN ALKIŞLAYALIM!, d) eğitim (eğ): Fahrettin Koca'nın takipçilerine sağlık bakanı olarak görev ve sorumluluklarını yerine getirdiğini ifade eden tweetler. Ör.: Önümüzdeki günlerde salgını ve tedbirleri çok farklı yönlerden ele alacağımız, Bilim Kurulu'na benzer, niteliği ayrı ikinci bir Bilim Kurulu kurmuş olacağız. Bu kurulda, olayın psikolojik, sosyolojik, istatistiksel... boyutları değerlendirilecek. Yeni yaklaşımlar arayacağız.

\subsubsection{Bulank Kümelerle ilgili Temel Kavramlar}

Belirsizlik kavramı sistemdeki bilgiye ilişkin düzey eksikliği ile yetersizliğinden kaynaklanmaktadır. Zaman içerisinde değişeme uğrayan sistemler, insanın biyolojisinden kaynaklı duyuşsal sınırlar, teknolojik eksikler belirsizlik kavramının her alanda olmasına neden olabilmektedir (Zadeh, 1965). Bu bakımdan belirsizlik ya da kendisinden kaynaklanan belirsizliğin rasyonalitesine ilişkin bulanık küme teorisi Zadeh (1965) tarafından ortaya konmuştur. Karmaşıklık ve belirsizlik içeren büyüklükler, bir kümeye ait olma derecesini gösteren üyelik fonksiyonları ile açıklanmaya başlanmıştır (Zadeh, 1965). Belirsizlik içeren sistemlerin çözümü bu yeni küme tanımıyla yen bir boyut kazanmış olup otomatik kontrol sistemleri, bilgi sistemleri, ekonomi ve yönetim bilimlerinde kendine uygulama alanı bulmuştur.

Bu bağlamda, bulanık kümeler için sıradan veya 1'inci tip bulanık kümeler olarak isimlendirilen ilk bulanık kümelerde yer alan üyelik derecesinin tanımına getirilen eleştiriler, üyelik derecelerinin daha detaylı 


\section{S. Aydoğan - F. Kutlu Gündoğdu 13/2 (2021) 1737-1750}

tanımlanması yönünde ki çalışmalara hız kazandırmıştır. Bu çalışmalar içinde en önemlilerinden biri ise sezgisel bulanık kümelerdir. Bu noktada Atanassov (1986), sezgisel bulanık kümlerde karar vericilerin üyelik derecesini belirlenmesi kadar, üye olmama derecesini de belirleme durumunun olabileceğini ortaya koyarak karar vericilerin kararsızlık derecesinin de dikkate alınması gerektiğini vurgulamaktadır. Bu vurgunun çıktısı olarak artık üyelik ve üye olmama derecelerin toplamı bire eşit olmak zorunda değildir. Bunların toplamı ile bir arasındaki fark, "kararsızlık" olarak tanımlanmaktadır. Belirsizliğin daha fazla olduğu durumlarda ise aralık değerli sezgisel bulanık kümelerin kullanımının daha uygun olacağını vurgulamıştır. Aralık değerli bulanık kümeler, üyelik fonksiyonlarının tek bir nokta halinde değil, bir aralık olarak belirlenmesine izin vermektedir.

Aşağıda bu çalışmanın yönteminde kullanılacak olan bulanık kümeler ile ilgili tanımlar verilmiştir.

Tanım 3.1. $\mathrm{U}$ boş olmayan sonlu bir küme olsun. $\forall x \in U, 0 \leq \mu_{B}(x) \leq 1$ olmak üzere, $\mu_{B}(x): U \rightarrow[0,1]$ fonksiyonu ile bir bulanık küme

$\tilde{B}=\left\{\left\langle x, \mu_{B}(x)\right\rangle: x \in U\right\}$

ifadesi ile verilir. Burada $\mu_{B}(x), x \in U$ nun $B$ kümesine ait olma derecesidir.

Tanım 3.2. $U$ boş olmayan sonlu bir küme olsun. $\forall x \in U, 0 \leq \mu_{S}(x)+v_{S}(x) \leq 1$ olmak üzere, $\mu_{S}(x): U \rightarrow[0,1]$ ve $v_{S}(x): U \rightarrow[0,1]$ fonksiyonları ile tek değerli sezgisel bulanık küme;

$\tilde{S}=\left\{\left\langle x, \mu_{S}(x), v_{S}(x)\right\rangle: x \in U\right\}$

ifadesi ile verilir. Burada $\mu_{S}(x)$ ve $v_{S}(x)$ sırasıyla $x \in U$ nun üye olma ve üye olmama derecesidir. Ayrıca $\pi_{S}$ ile gösterilen kararsızlık derecesi $\pi_{S}(x)=1-\mu_{S}(x)-\vartheta_{S}(x)$ şeklinde hesaplanır.

Tanım 3.3. $U$ boş olmayan sonlu bir küme olsun. $\forall x \in U, 0 \leq \mu_{\tilde{A}}^{+}+v_{\tilde{A}}^{+} \leq 1$ olmak üzere, $\mu_{\tilde{A}}^{-}, \mu_{\tilde{A}}^{+}: U \rightarrow[0,1]$ ve $v_{\tilde{A}}^{\bar{A}}, v_{\tilde{A}}^{+}: U \rightarrow[0,1]$ fonksiyonları ile aralık değerli sezgisel bulanık küme;

$\tilde{A}=\left\{\left\langle x,\left[\mu_{\tilde{A}}, \mu_{\tilde{A}}^{+}\right],\left[v_{\tilde{A}}, v_{\tilde{A}}^{+}\right]\right\rangle: x \in U\right\}$

ifadesi ile verilir. Burada $\mu_{\tilde{A}}^{-}$ve $\mu_{\tilde{A}}^{+}$sirasiyla alt ve üst üyelik derecelerini temsil ederken, $v_{\tilde{A}}^{-}$ve $v_{\tilde{A}}^{+}$ise alt ve üst üye olmama derecelerini temsil eder.

Tanım 3.4. $\tilde{A}=\left\{\left[\mu_{\tilde{A}}^{-}, \mu_{\tilde{A}}^{+}\right],\left[v_{\tilde{A}}^{-}, v_{\tilde{A}}^{+}\right]\right\}$ve $\tilde{B}=\left\{\left[\mu_{\tilde{B}}^{-}, \mu_{\tilde{B}}^{+}\right],\left[v_{\tilde{B}}^{-}, v_{\tilde{B}}^{+}\right]\right\}$kümeleri $\mathrm{U}$ üzerinde iki aralık değerli sezgisel bulanık küme olsun. Bu iki sezgisel bulanık küme üzerine işlemler aşağıdaki gibi tanımlanır:

$\tilde{A} \oplus \tilde{B}=\left(\left[\mu_{\tilde{A}}^{-}+\mu_{\tilde{B}}^{-}-\mu_{\tilde{A}}^{-} \mu_{\tilde{B}}^{-}, \mu_{\tilde{A}}^{+}+\mu_{\tilde{B}}^{+}-\mu_{\tilde{A}}^{+} \mu_{\tilde{B}}^{+}\right],\left[v_{\tilde{A}}^{-} v_{\tilde{B}}^{-}, v_{\tilde{A}}^{+} v_{\tilde{B}}^{+}\right]\right)$

$\tilde{A} \otimes \tilde{B}=\left(\left[\mu_{\tilde{A}}^{-} \mu_{\tilde{B}}^{-}, \mu_{\tilde{A}}^{+} \mu_{\tilde{B}}^{+}\right],\left[v_{\tilde{A}}^{-}+v_{\tilde{B}}^{-}-v_{\tilde{A}}^{-} v_{\tilde{B}}^{-}, v_{\tilde{A}}^{+}+v_{\tilde{B}}^{+}-v_{\tilde{A}}^{+} v_{\tilde{B}}^{+}\right]\right)$

\subsubsection{Aralık Değerli Sezgisel Bulanık Analitik Hiyerarşi Süreci (AHS) Aşamaları}

İlk aşamada, çalışmada aralık değerli sezgisel analitik hiyerarşi süreci ile sergilenen liderliğe ilişkin boyutların önem dereceleri ölçülmüsştür. Yöntemde kullanılacak olan bulanık dilsel ifadeler skalası Tablo 2' de verilmiştir.

Tablo 2. Sezgisel Bulanık Dilsel İfadeler ve Bulanık Aralık Değerleri

\begin{tabular}{llc}
\hline Dilsel ifadeler & $\begin{array}{l}\text { Aralık değerli sezgisel bulanık } \\
\text { sayılar }\end{array}$ & $\begin{array}{c}\text { Klasik Sayı } \\
\text { Karşılıkları }\end{array}$ \\
\hline Kesin Önemli $(\mathrm{CH})$ & $\{[0.65,0.75],[0.10,0.25]\}$ & 9 \\
Çok Kuvvetli Derece Önemli (VH) & $\{[0.60,0.70],[0.15,0.30]\}$ & 7 \\
Kuvvetli Derece Önemli (H) & $\{[0.55,0.65],[0.20,0.35]\}$ & 5 \\
Orta Derece Önemli (AM) & $\{[0.50,0.60],[0.25,0.40]\}$ & 3 \\
Esit Önemli (EE) & $\{[0.50,0.50],[0.50,0.50]\}$ & 1 \\
Orta Derece Önemsiz (BM) & $\{[0.25,0.40],[0.50,0.60]\}$ & $1 / 3$ \\
Kuvvetli Derece Önemsiz (L) & $\{[0.20,0.35],[0.55,0.65]\}$ & $1 / 5$ \\
Çok Kuvvetli Derece Önemsiz (VL) & $\{[0.15,0.30],[0.60,0.70]\}$ & $1 / 7$ \\
Kesin Önemsiz (CL) & $\{[0.10,0.25],[0.65,0.75]\}$ & $1 / 9$ \\
\hline
\end{tabular}

Kaynak: Karasan vd., 2018. 
Adım 1. Tablo 2'deki dilsel ifadeleri kullanarak karar vericiler belirlenen kategoriler veya bir diğger deyişle

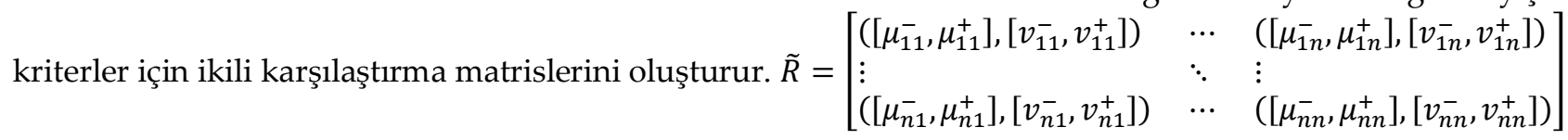
(6)

Adım 2. Oluşturulan ikili karşılaştırma matrislerinin önce tutarlılık oranı (CR) hesaplanır. Tutarlılık oranı 0.10'dan küçükse Adım 3'e geçilir, değilse Adım 1'e geri dönülür. Tutarlılık oranını hesaplamak için;

$\left(\tilde{R}-\lambda_{\max } . I\right) \mathrm{w}_{\mathrm{i}}=0$

(7) $C I=\frac{\lambda_{\max }}{n-1}$

$C R=\frac{C I}{R I}$

$\lambda_{\max }$ maksimum öz değer, $w_{\mathrm{i}} \tilde{R}$ matrisinin öz vektörü, $R I$ rassal tutarlılık indeksi ve $I$ ise birim matristir. Rassal tutarlılık indeksi için Tablo 3 kullanılmıştır.

Tablo 3. Rassal Tutarlılık İndeksi (RI)

\begin{tabular}{ccccccccc}
\hline $\mathbf{n}$ & $\mathbf{2}$ & $\mathbf{3}$ & $\mathbf{4}$ & $\mathbf{5}$ & $\mathbf{6}$ & $\mathbf{7}$ & $\mathbf{8}$ & $\mathbf{9}$ \\
\hline RI & 0 & 0.58 & 0.9 & 1.12 & 1.24 & 1.32 & 1.41 & 1.45 \\
\hline
\end{tabular}

Adım 3. İkili karşılaştırma matrislerinin skor değerleri Denklem (10) kullanılarak hesaplanır.

$\tilde{S}=\left[\tilde{s}_{i j}\right]=\left[\begin{array}{lll}{\left[\mu_{11}^{-}-v_{11}^{+}, \mu_{11}^{+}-v_{11}^{-}\right]} & \cdots & {\left[\mu_{1 n}^{-}-v_{1 n}^{+}, \mu_{1 n}^{+}-v_{1 n}^{-}\right]} \\ \vdots & \ddots & \vdots \\ {\left[\mu_{n 1}^{-}-v_{n 1}^{+}, \mu_{n 1}^{+}-v_{n 1}^{-}\right]} & \cdots & {\left[\mu_{n n}^{-}-v_{n n}^{+}, \mu_{n n}^{+}-v_{n n}^{-}\right]}\end{array}\right]$

Adım 4. Aralık çarpım matrisi Denklem (11)'e ve Adım 3'te hesaplanan skor değerlerine göre bulunur.

$\tilde{A}=\left[\tilde{a}_{i j}\right]=\left[\begin{array}{lll}{\left[10^{\mu_{11}^{-}-v_{11}^{+}}, 10^{\mu_{11}^{+}-v_{11}^{-}}\right]} & \cdots & {\left[10^{\mu_{1 n}^{-}-v_{1 n}^{+}}, 10^{\mu_{1 n}^{+}-v_{1 n}^{-}}\right]} \\ \vdots & \ddots & \vdots \\ {\left[10^{\mu_{n 1}^{-}-v_{n 1}^{+}}, 10^{\mu_{n 1}^{+}-v_{n 1}^{-}}\right]} & \cdots & {\left[10^{\mu_{n n}^{-}-v_{n n}^{+}}, 10^{\mu_{n n}^{+}-v_{n n}^{-}}\right]}\end{array}\right]$

Adım 5. Denklem (12) kullanılarak her bir kategorinin aralık önem derecesi hesaplanır.

$\widetilde{w}_{i}=\left[w_{i}^{+}, w_{i}^{-}\right]=\left[\frac{\sum_{j=1}^{n} \tilde{a}_{i j}^{-}}{\sum_{i=1}^{n} \sum_{j=1}^{n} \tilde{a}_{i j}^{+}}, \frac{\sum_{j=1}^{n} \tilde{a}_{i j}^{+}}{\sum_{i=1}^{n} \sum_{j=1}^{n} \tilde{a}_{i j}^{-}}\right]$

Adım 6. Olabilirlik derecesi matrisi $\left(0=\left[o_{i j}\right]\right)$ Denklem (13) kullanılarak hesaplanır.

$O\left(w_{i} \geqslant w_{j}\right)=\frac{\min \left\{\mathrm{P}_{w_{i}}+\mathrm{P}_{w_{j}} \max \left(w_{i}^{+}-w_{j}^{-}, 0\right)\right\}}{P_{w_{i}}+\mathrm{P}_{w_{j}}}$

Denklem 13, $P_{w_{i}}=w_{i}^{+}-w_{i}^{-}, P_{w_{j}}=w_{\mathrm{j}}^{+}-w_{\mathrm{j}}^{-}$ve $o_{i j}+o_{j i}=1$ olduğu şartlarda geçerlidir.

Adım 7. Denklem (14) kullanılarak her bir kategorinin ağırlığı hesap edilir.

$w_{i}=\frac{1}{n}\left[\sum_{j=1}^{n} o_{i j}+\frac{n}{2}-1\right]$

Adım 8. Bulunan kategori ağırlıkları Denklem (15) yardımıyla normalize edilir.

$\bar{w}_{i}=\frac{w_{i}}{\sum_{\mathrm{i}=1}^{\mathrm{n}} w_{i}}$

\section{ARALIK DEĞERLİ SEZGİSEL BULANIK AHP ANALİİ VE BULGULAR}

Çalışmamızda Fahrettin Koca'nın Twitter paylaşımları ile sergilediği liderlik içeriklerinin analizi, Bass ve Avilio (1994) tarafından ortaya konan beş boyutu dönüşümsel liderlik üzerinden incelenmiştir. Bunlar; vizyon (viz), öykünme (öyk), amaç (amç), eylem (eyl) ve eğitim (eğt)'dir. İlk olarak bu beş boyutun ağırlıkları hesaplanacaktır. Bunun için çalışmada, deneyimli uzmanların görüşünden yararlanarak toplum sağlığının edinilmesine yönelik sergilenen liderlik boyutlarının etkinlik kriterleri belirlenmiş ve klasik ikili karşılaştırma yöntemi ile kriterlerin önem seviyeleri elde edilmiştir. Bunun için üç uzman görüşüne başvurulmuştur. Uzman 1 ve Uzman 2 yönetim bilimci iken Uzman 3 ise tıp doktorudur. Tüm uzmanlar eşit önem derecesine sahip olduğu varsayılmıştır. Uzmanların (uzm) kendi deneyimlerini ve Tablo 2' deki dilsel ifadeleri temel alarak doldurduğu ikili karşılaştırma matrisleri Tablo 4 'te verilmektedir. 
Tablo 4. Uzmanlara Göre İkili Karşılaştırma Matrisleri

\begin{tabular}{cccccccccccc}
\hline Uzm1 & Viz & Eyl & Amç & Öyk & Eğt & Uzm2 & Viz & Eyl & Amç & Öyk & Eğt \\
\hline Viz & EE & H & H & L & L & Viz & EE & H & H & L & L \\
Eyl & L & EE & EE & VL & VL & Eyl & L & EE & EE & VL & VL \\
Amç & L & EE & EE & VL & VL & Amç & L & EE & EE & VL & VL \\
Öyk & H & VH & VH & EE & EE & Öyk & H & VH & VH & EE & EE \\
Eğt & H & VH & VH & EE & EE & Eğt & H & VH & VH & EE & EE \\
\hline Uzm3 & Viz & Eyl & Amç & Öyk & Eğt & - & - & - & - & - & - \\
\hline Viz & EE & AM & H & AM & EE & - & - & - & - & - & - \\
Eyl & BM & EE & AM & EE & L & - & - & - & - & - & - \\
Amç & L & BM & EE & BM & EE & - & - & - & - & - & - \\
Öyk & BM & EE & AM & EE & H & - & - & - & - & - & - \\
Eğt & EE & AM & H & AM & EE & - & - & - & - & - & - \\
\hline
\end{tabular}

Tablo 4'teki ikili karşılaştırma matrisleri tutarlılık analizi yapabilmek için klasik sayılara dönüştürülmüştür. Örneğin; AM yerine 3 yazılırken L yerine 1/5 yazılır. Maksimum öz değerleri hesaplanan matrislerin tutarlılık indeksi Adım 2'ye göre hesaplanmıştır. Uzman 1'in ikili karşılaştırma matrisinin tutarlılık oranı 0,09 çıkarken Uzman 2 ve Uzman 3'ün tutarlılık oranı ise 0,01 çıkmıştır. Üç matriste tutarlı olduğundan Adım 3'e devam edilmiştir. Uzman 1, Uzman 2 ve Uzman 3 için Adım 3'ten Adım 8'e kadar yapılan tüm hesaplamalar detaylı olarak Tablo 5'te verilmiştir.

Tablo 5. Uzman 1, Uzman 2 ve Uzman 3'ün Görüşlerine Dayanılarak Oluşturulan Kategori Ağırlıkları

\begin{tabular}{cccccccccccc}
\hline Uzm 1-2 & $w^{+}$ & $w^{-}$ & $\mathrm{P}_{\mathrm{w}}$ & $w_{i}$ & $\bar{w}_{i}$ & Uzm 3 & $w^{+}$ & $w^{-}$ & $\mathrm{P}_{\mathrm{w}}$ & $w_{i}$ & $\bar{w}_{i}$ \\
\hline Viz & 0,31 & 0,13 & 0,18 & 0,77 & 0,221 & Viz & 0,38 & 0,18 & 0,20 & 0,99 & 0,283 \\
Eyl & 0,14 & 0,07 & 0,07 & 0,41 & 0,118 & Eyl & 0,23 & 0,12 & 0,11 & 0,67 & 0,191 \\
Amç & 0,14 & 0,07 & 0,07 & 0,41 & 0,118 & Amç & 0,17 & 0,10 & 0,08 & 0,46 & 0,130 \\
Öyk & 0,46 & 0,19 & 0,27 & 0,95 & 0,271 & Öyk & 0,32 & 0,16 & 0,16 & 0,90 & 0,256 \\
Eğt & 0,46 & 0,19 & 0,27 & 0,95 & 0,271 & Eğt & 0,17 & 0,11 & 0,06 & 0,49 & 0,139 \\
\hline
\end{tabular}

Tablo 5'deki boyut ağırlıklarını birleştirmek için aritmetik ortalama kullanılmış ve sergilenen liderlik boyutlarının ağırlığı uzmanlara göre öykünme için $0,266^{*}$, vizyon için $0,242^{* *}$, eğitim için 0,227 , eylem için 0,142 ve amaç için $0,122^{\prime}$ dir.

$\mathrm{Bu}$ çalışmada araştırmanın amacına uygun olarak araştırılan bir diğer husus ise Twitter paylaşımı ile sergilediği liderliğin takipçileri ile etkileşiminde retweet, beğeni ve yorumun önem derecelerinin belirlenmesidir. Bir tweete gelen beğeni ile yorumun önem derecesinin eşit olduğu varsayılamaz. Bu unsurların ağırlıklarını belirlemek için yönetim biliminden 3 uzman ikili karşılaştırma matrislerini doldurmuştur. Oluşturulan matrislerin tutarlılık oranları beğeni için 0.033 , yorum için 0.025 ve retweet için ise 0.011 olarak hesaplanmıştır. Liderlik boyutları için uygulanan adımlar tekrar edildiğinde beğeni sayısının önem derecesi 0,278, yorum sayısının önem derecesi 0,240 iken retweet sayısının önem derecesi ise 0,482 olarak hesaplanmıştır. Üç uzmanımızın ortak kararına göre retweet sayısının fazlalığı o tweetin önemini en fazla arttıran etmendir. Her bir liderlik boyutundaki sayılar kendi ağırlığıyla çarpılıp normalize edilerek ağırlıklı ortalama hesaplanmış ve Tablo 7'de verilmiştir. Ör; Eylem boyutu için $17495.92 * 0,240+29361.337 *$ $0,482+293336.8 * 0,278=99961.1582$ olarak hesaplanir.

Tablo 6. @drfahrettinkoca Kullanıcısının Tweet, Yorum, Retweet ve Beğeni Sayısı

\begin{tabular}{lllllll}
\hline \multirow{2}{*}{ Boyutlar } & Toplam & Toplam & & \multicolumn{3}{c}{. } \\
& Tweet & Yorum & Toplam Retweet & \multicolumn{2}{c}{ Toplam Beğeni Ağırlıklandırılmış Ağırlıkla } \\
& Sayısı & Sayısı & Sayıs & Sayısı & Ortalama & r \\
\hline Eylem & 197 & 17495.92 & 29361.34 & 293336.8 & 99961.1582 & 0,102 \\
Eğitim & 291 & 33506.39 & 45937.13 & 366408.6 & 132120.1444 & 0,136 \\
Öykünme & 188 & 18021.3 & 36476.98 & 391728.3 & 130891.8369 & 0,135 \\
Amaç & 207 & 36548.4 & 67874.6 & 661944 & 225648.753 & 0,232 \\
Vizyon & 299 & 54892.1 & 109474.8 & 1138028 & 382557.08 & $0,393^{*}$ \\
\hline Genel Toplam & 1182 & 160464.1 & 289124.9 & 2851445 & 971178.973 & 1 \\
\hline
\end{tabular}




\section{S. Aydoğan - F. Kutlu Gündoğdu 13/2 (2021) 1737-1750}

Tablo 6'ye göre Fahrettin Koca'nın sergilediği liderlik boyutları ile ilişkilendirilen tweetlerin önem dereceleri incelendiğinde en yüksek önemin $0.393^{*}$ ağırlıkla vizyon oluşturma amacı taşıyan tweetler olduğu söylenebilir. Sırasıyla paylaşılan tweetlerin takipçileri üzerindeki etkileri sergilediği liderlik tarzının boyutlarına göre 0,232 ağırlıkla amaç, 0,136 ağırlıkla eğitim, 0,135 ağırlıkla öykünme, 0.102 ağırlıkla eylemdir.

Son aşamada paylaşılan tweetlerin hesaplanan ağırlıklı önem dereceleri ile her bir boyutun önem derecesi (Tablo 6'daki ağırlıklarla) çarpılmış ve Sağlık bakanı Fahrettin Koca'nın sergilediği liderlik boyutlarının takipçileri üzerindeki etkisi yüzde olarak elde edilmiştir (Ör.;Viz: 0,393x0,242). Elde edilen yüzdeler Tablo 7'de verilmektedir.

Tablo 7. Sergilenen Liderlik Boyutlarının Etki Yüzdeleri

\begin{tabular}{cc}
\hline Kategoriler & Dijital Liderlik Etki Yüzdeleri \\
\hline Vizyon & $\% 46.46$ \\
\hline Öykünme & $\% 17.51$ \\
\hline Eğitim & $\% 15.07$ \\
\hline Amaç & $\% 13.81$ \\
\hline Eylem & $\% 7.14$ \\
\hline
\end{tabular}

Tablo 7'ye göre Fahrettin Koca'nın paylaştığı tweetlerin takipçileri üzerindeki etkileri göz önüne alındığında en çok \%46.46 oran ile vizyon, \%17.51 oran ile öykünme, $\% 15.07$ oran ile eğitim, \%13.81 oran ile amaç ve \%7.14 oran ile eylem liderlik boyutudur.

\section{SONUÇ VE TARTIŞMA}

Tüm dünyada ani gelişen Covid-19 salgını ve hızla artan etkisi toplum sağlığının edinilmesine yönelik davranışlarda belirsizliklere neden olmaktadır. Bu belirsizliğin giderilmesi Sağlık Bakanlığının sorumluluk alanıdır. Salgın sürecinde Twitter, Fahrettin Koca tarafından bilgi ve yönlendirme eksikliğinin giderilmesinde önemli bir liderlik aracı olarak kullanılmaktadır. Twitter' in kullanımı toplum sağlığının edinilmesine yönelik çabalara katkı sağlayarak takipçilerinin salgınla mücadelesini bilimsel esaslar göre şekillendirebilmektedir.

Bu kapsamda, Fahrettin Koca'nın Twitter üzerinden salgın ile mücadelede sergilediği dijital liderlik ve bu liderliğin boyutları ile ilişkili tweetlerin beğeni, yorum ve retweet sayıları gözetildiğinde Fahrettin Koca en fazla vizyon liderlik boyutuna önem vermektedir. Vizyon belirgin bir başarı tanımı içerdiğinden (Kaplan vd., 2008) takipçiler için bir vizyon sağlamak kriz yönetiminin başarısı için önem arz etmektedir (Al Shobaki vd. 2016). Uygulanabilir bir vizyon belirlemek Fahrettin Koca'nın takipçilerini halk sağlığının edinilmesi gibi bir amaç için güçlendirmekte, onları motive etmekte ve gelecek için gerekli değişikliği zihinlerinde oluşturmaktadır (Altıok, 2011). Ayrıca salgınla mücadele sırasında Fahrettin Koca'nın toplumu bilgilendirmesi, salgın ile mücadelede proaktif, bütüncül ve dinamik bir yaklaşım benimsemesi ve elde edilen tecrübeleri salgının sonlandırılması için toplum ile paylaşma tercihi (Koca, 2020) söz konusudur. Bu sonuç uzman görüşüne göre oluşturulması beklenen liderlik boyutunda farklıdır. Çünkü uzmanlar ile Fahrettin Koca uyumsuz ilgiye sahip olabilirler (Rocha vd., 2016: 59).

Bununla birlikte Fahrettin Koca'nın Twitter üzerinden salgın ile mücadelede sergilediği dijital liderlik boyutlarından takipçileri üzerinde en fazla etkiye sahip olan boyut yine vizyon boyutudur. Salgın ile mücadele de etkin bir liderlik için vizyon ortaya koyma stratejisi Fahrettin Koca takipçilerini halk sağllğının edinilmesi için etkilemekte, vizyon sağlama bağlamında ki tweetleri ise "tweet ilginçliği" (Webberley vd., 2016) yaratmakta, yenilikçi araçlar (ör; uzaktan çalışma, esnek mesai, sosyal mesafe, izolasyon, tam ve kısmi kapanma vb.) ve kaynaklar sağlamaktadır (Cote, 2017). Fahrettin Koca'nın dijital liderlik boyutlarından takipçileri üzerinde en fazla etkiye sahip olan boyutun vizyon boyutu olması Twitter takipçilerinin salgın ile mücadelenin başarılı ile sonuçlandırılmasına ilişkin inanç ve ilgileri ile ilgilidir. Çünkü Fahrettin Koca'nın takipçileri vizyon sağlayan tweetleri retweet ederek kendi takipçilerini bir düzeyde harekete geçirebileceğine inanmakta ve bu şekilde vizyon sağlayan tweetleri takipçileri kişiselleştirmektedir (Webberley vd., 2016).

Çalışmanın amacı kapsamında elde edilen bir diğer sonuç ise retweet sayısının önem derecesinin beğeni ve yorum sayısının önem derecesinden yüksek olmasıdır. Fahrettin Koca'nın takipçi sayısının salgın sürecinde önemli ölçüde arttığı göz önüne alındığında retweet sayısının önem derecesinin yüksek olması (Narbona, 2016) salgın ile mücadeleye yönelik bireylerin davranışlarına yön vermek konusunda bir fikir vermektedir 


\section{S. Aydoğan - F. Kutlu Gündoğdu 13/2 (2021) 1737-1750}

(Bruston, 2015; Kwak vd., 2010). Çünkü herhangi bir takipçinin paylaşılan tweeti retweet etmesi takipçiyi takip edenlerinde tweeti değerlendirmeye alma potansiyelini yaratmaktadır. Twitter'dan etkilenen sayısız insan olduğu değerlendirildiğinde Fahrettin Koca'nın Twitter paylaşımları ile salgınla mücadeleye vermek istediği yönün anlaşılması önem kazanmaktadır. Anılan önem aynı zamanda sosyal medyada daha derin bir liderlik anlayışının incelenmesine katkı sağlayacaktır.

\section{KAYNAKÇA}

Agarwal, V., Sharma, S., Gupta, L., Misra, D. P., Davalbhakta, S., Agarwal, V., ... and Aggarwal, S. (2020). COVID-19 and psychological disaster preparedness-an unmet need. Disaster Medicine And Public Health Preparedness, 14(3), 387-390.

Aksal, F. A. (2015). Are headmasters digital leaders in school culture? Education and Science/Egitim ve Bilim, 40(182), 77-86.

Albers, S., and Rundshagen, V. (2020). European airlines' strategic responses to the COVID-19 pandemic (January-May, 2020). Journal of Air Transport Management, 87, 101863.

Altıok, P. (2011). Applicable vision, mission and the effects of strategic management on crisis resolve. ProcediaSocial and Behavioral Sciences, 24, 61-71.

Al Shobaki, M. J., Amuna, Y. M. A., and Badah, W. (2016). The impact of the strategic orientations on crisis management agency, International Relief in Gaza.

Ardi, A., Djati, S. P., Bernarto, I., Sudibjo, N., Yulianeu, A., Nanda, H. A., and Nanda, K. A. (2020). The relationship between digital transformational leadership styles and knowledge-based empowering interaction for increasing organisational innovativeness. International Journal of Innovation, Creativity and Change, 11(3), 259-277.

Atanasov, K.T (1986) Intuitionistic fuzzy sets. Fuzzy Sets Syst, 20, 87-96.

Barbuto Jr, J. E. (2005). Motivation and transactional, charismatic, and transformational leadership: A test of antecedents. Journal of Leadership and Organizational Studies, 11(4), 26-40.

Bass, B. M., and B. J. Avolio. (1994). Improving Organizational Effectiveness Through Transformational Leadership. California, Sage.

Bilgiç, A., ve Akyüz, S. S. (2020) Türkiye'de covid-19 pandemisi döneminde sağlık bakanı fahrettin koca'nın sosyal medya kullanımı: twitter paylaşımları içerik analizi. Gaziantep Üniversitesi Sosyal Bilimler Dergisi, 19(COVID-19 Special Issue), 230-243.

Blog.Protan (2021). Mikroblog nedir?, https://blog.protan.com.tr/mikro-blog-nedir/ (Erişim tarihi: 5 Mart 2021).

Bruston, M. (2015). Twiplomacy Study 2015 https://twiplomacy.com/blog/twiplomacy-study-2015/ (Erişim tarihi: 5 Mart 2021).

Boomsocial (2021) Dr. Fahrettin Koca https://www.boomsocial.com/Twitter/Hesap/drfahrettinkoca1016198241417822208 (Erişim tarihi 5 Mart 2021).

Bostan, S., Erdem, R., Öztürk, Y. E., Kılıç, T., and Yılmaz, A. (2020). The effect of covıd-19 pandemic on the Turkish society. Electronic Journal of General Medicine, 17(6).

Cinelli, M., Quattrociocchi, W., Galeazzi, A., Valensise, C. M., Brugnoli, E., Schmidt, A. L., Paola Zola6, Fabiana Zollo1,2,7 and Scala, A. (2020). The covid-19 social media infodemic. Scientific Reports, 10(1), 1-10.

Cha, M., Haddadi, H., Benevenuto, F., and Gummadi, K. (2010). Measuring user influence in twitter: The million follower fallacy. In Proceedings of the International AAAI Conference on Web and Social Media, USA, 23-26 May 2010, Washington, George Washington Univercity, 10-17.

Claussv, F. J. (2010). Corporate Financial Analysis With Microsoft Excel. New York The McGraw-Hill Companies, Inc. 2. 


\section{S. Aydoğan - F. Kutlu Gündoğdu 13/2 (2021) 1737-1750}

Coad, A. F., and Berry, A. J. (1998). Transformational leadership and learning orientation. Leadership and Organization Development Journal, 164-172.

Conger, J. A., Kanungo, R. N., and Menon, S. T. (2000). Charismatic leadership and follower effects. Journal of Organizational Behavior: The International Journal of Industrial, Occupational and Organizational Psychology and Behavior, 21(7), 747-767.

Cote, R. (2017). Vision of effective leadership. International Journal of Business Administration, 8(6), 1-10.

da Rocha, P. M., de Barros, A. P., da Silva, G. B., and Costa, H. G. (2016). Analysis of the operational performance of brazilian airport terminals: A multicriteria approach with De Borda-AHP integration. Journal Of Air Transport Management, 51, 19-26.

Fikret Pasa, S., Kabasakal, H., and Bodur, M. (2001). Society, organisations, and leadership in Turkey. Applied Psychology, 50(4), 559-589.

Gamayanto, I., Christian, H., Wibowo, S., and Purnamasari, D. (2019). Developing "leadership intelligence (CI2) framework" inside social media to develop an ethical leader using the johari window method. Indonesian Journal of Information Systems, 1(2), 119-132.

Gilbert, S. L., and Kelloway, E. K. (2018). Leadership, recognition and well-being: A moderated mediational model. Canadian Journal of Administrative Sciences/Revue canadienne des sciences de l'administration, 35(4), 523-534.

Goodwin, V. L., Whittington, J. L., Murray, B., and Nichols, T. (2011). Moderator or mediator? Examining the role of trust in the transformational leadership paradigm. Journal of Managerial Issues, 409-425.

Herold, D. M., Fedor, D. B., Caldwell, S. D., and Liu, Y. (2008). The effects of transformational leadership and change leadership on employees' commitment to a change: A multilevel study. Journal of Applied Psychology, 93, 346-357.

Hootsuite Dijital (2020). Küresel kullanım raporu, https://hootsuite.com/pages/digital-2020\#c192448 (Erişim tarihi: 22 Şubat 2021).

Hwang, Y. 2015. Does opinion leadership increase the followers on Twitter. International Journal of Social Science and Humanity, 5, 258-264.

Ingerson, K. and J. Bruce. (2013). Leadership in the Twitterverse. Journal of Leadership Studies, 7: 74-83.

Kalsoom, Z., Khan, M. A., and Zubair, D. S. S. (2018). Impact of transactional leadership and transformational leadership on employee performance: A case of FMCG industry of Pakistan. Industrial Engineering Letters, 8(3), 23-30.

Kalçık, T., and Bayraktar, Ü. A. (2020). Covid-19 salgınının yönetilmesinde sosyal medya kullanımı: sağlık bakanı Fahrettin koca'nın resmi Twitter hesabı üzerine bir analiz. Electronic Turkish Studies, 15(6), 583602.

Kaplan, R. S., Norton, D. P., and Barrows, E. A. (2008). Developing the strategy: Vision, value gaps, and analysis. Balanced scorecard report, 10(1), 1-5.

Karasan, A., Erdogan, M., and Ilbahar, E. (2018). Prioritization of production strategies of a manufacturing plant by using an integrated intuitionistic fuzzy AHP and TOPSIS approach. Journal of Enterprise Information Management. 510-528.

Kim, Y. (2011). The contribution of social network sites to exposure to political difference: The relationships among SNSs, online political messaging, and exposure to cross-cutting perspectives. Computers in Human Behavior, 27 (2), 971-977.

Koca, F. (2020). Turkey's management of covid-19. Insight Turkey, 22(3), 55-66.

Koh, H. K., and Jacobson, M. (2009). Fostering public health leadership. Journal Of Public Health, 31(2), 199-201. 


\section{S. Aydoğan - F. Kutlu Gündoğdu 13/2 (2021) 1737-1750}

Koh, H. K., and McCormack, M. (2006). Public health leadership in the 21st century. In: Kellerman B (ed). Working Papers of the Center for Public Leadership. Cambridge, MA: Harvard University Kennedy School of Government, 2006, $101-16$.

Kotter, J. P. (2011). What leaders really do. Harvard Business Review, 79(11).

Kutikov, A., Weinberg, D. S., Edelman, M. J., Horwitz, E. M., Uzzo, R. G., and Fisher, R. I. (2020). A war on two fronts: cancer care in the time of COVID-19. Ann Intern Med, 172, 756-758.

Kwak, H., Lee, C., Park, H., and Moon, S. (2010). What is Twitter, a social network or a news media?. In Proceedings of The 19th International Conference On World Wide Web, in Raleigh North Carolina, USA, 2630 April, New York, 591-600.

Lewis, Seth C., Zamith, Rodrigo, and Hermida, Alfred. (2013). Content analysis in an era of big data: A hybrid approach to computational and manual methods. Journal of Broadcasting and Electronic Media, 57, 34-52.

Mayer-Schoenberger, V., and Oberlechner, T. (2002). Through their own words: Towards a new understanding of leadership through metaphors. John F. Kennedy School of Government, Harvard University, Faculty Research Working Papers Series, 159-175.

Masa'deh, R. e., Obeidat, B. Y., and Tarhini, A. (2016). A Jordanian empirical study of the associations among transformational leadership, transactional leadership, knowledge sharing, job performance, and firm performance. Journal of Management Development, 35(5), 681-705.

Merriam-webster (2021). Microblogging, https://www.merriamwebster.com/dictionary/microblogging\#: :text=\%3A\%20blogging\%20done\%20with\%20severe\%20spac e,Sentences\%20Learn\%20More\%20about\%20microblogging, (Erişim tarihi: 5 Mart 2021).

Metcalf, M. (2008). Level 5 Leadership: Leadership that Transforms Organizations and Creates Sustainable Results. Integral Leadership Review, 8(2), 2008-03.

Middleton, J., Lopes, H., Michelson, K., and Reid, J. (2020). Planning for a second wave pandemic of COVID19 and planning for winter. International Journal of Public Health, 65(9), 1525-1527.

Narbona, J. (2016). Digital leadership, twitter and Pope Francis. Church, Communication and Culture, 1(1), 90109.

Nathan, M. (2000). The paradoxical nature of crisis. Review of Business, 21(3/4), 12-16.

Northouse, P. G. 2015. Leadership: Theory and Practice. California, Sage

Neuendorf, K. A., and Kumar, A. (2015). Content analysis. The International Encyclopedia of Political Communication, 1-10.

Özsalmanlı, A., Y. (2005). Türkiye'de kamu yönetiminde liderlik ve lider yöneticilik. Manas Üniversitesi Sosyal Bilimler Dergisi, 7(13), 137-146.

Parks, S.D. (2005). Leadership Can Be Taught: A Bold Approach For A Complex World. Boston, Harvard Business School Press.

Park, C. S. (2013). Does Twitter motivate involvement in politics? Tweeting, opinion leadership, and political engagement. Computers in Human Behavior, 29(4), 1641-1648.

Pescosolido, A. T. (2001). Informal leaders and the development of group efficacy. Small Group Research, 32(1), 74-93.

Remuzzi, A., and Remuzzi, G. (2020). COVID-19 and Italy: what next?. The lancet, 395(10231), 1225-1228.

Seltzer, J., and Bass, B. M. (1990). Transformational leadership: Beyond initiation and consideration. Journal of management, 16(4), 693-703.

Sharot, T. and Sunstein, C. R. How people decide what they want to know. Nat. Hum. Behav. 2020, 1-6 (2020).

Smircich, L., and Morgan, G. (1982). Leadership: The management of meaning. Journal of Applied Behavioral Science, 18, 257-273. 


\section{S. Aydoğan - F. Kutlu Gündoğdu 13/2 (2021) 1737-1750}

Socialblade (2021). Dr. Fahrettin Koca, https://socialblade.com/twitter/user/drfahrettinkoca, (Erişim tarihi: 07 Mart 2021).

Suárez, L. M. C., López, J. P., and Cambronero Saiz, B. (2020). The influence of heuristic judgments in social media on corporate reputation: A study in spanish leader companies. Sustainability, 12(4), 1640.

Thite, M. (2000). Leadership styles in information technology projects. International Journal of Project Management, 18(4), 235-241.

Twiplomacy (2020). Twiplomacy Study 2020 https://twiplomacy.com/blog/twiplomacy-study-2020/, (Erişim tarihi: 21 Mart 2021).

Uzun, N. D., Tekin, M., Sertel, E., and Tuncar, A. (2020). Psychological and social effects of COVID-19 pandemic on obstetrics and gynecology employees. J Surg Med, 4(5), 355-358.

Van Eeden, R., Cilliers, F., and Van Deventer, V. (2008). Leadership styles and associated personality traits: Support for the conceptualisation of transactional and transformational leadership. South African Journal of Psychology, 38(2), 253-267.

Webberley, W. M., Allen, S. M., and Whitaker, R. M. (2016). Retweeting beyond expectation: Inferring interestingness in Twitter. Computer Communications, 73, 229-235.

Wenzel, M., Stanske, S., and Lieberman, M. B. (2020). Strategic Responses To Crisis. Strategic Management Journal, 7-18.

Wirtz, B. W., Göttel, V., Langer, P. F., and Thomas, M. J. (2020). Antecedents and consequences of public administration's social media website attractiveness. International Review of Administrative Sciences, 86(1), 38-61.

Williams, D. (2005). Real leadership: Helping people and organizations face their toughest challenges. Oakland, Berrett-Koehler Publishers.

World Health Organization Organization (2020), Naming the coronavirus disease (COVID-19) and the virus that causes it. https ://www.who.int/emerg encies/diseases/novel-coronavirus-2019/technicalguidance/naming-the-coron avirus-disease-(covid -2019)-and-the-virus -that-causes-it, (Erişim tarihi: 22 Şubat 2020).

Zadeh, L. A. (1965). Information and control. Fuzzy sets, 8(3), 338-353.

Zarocostas, J.(2020) How to fight an infodemic. Lancet 395, 676 